\title{
The use of artificial habitats increases spider abundance and richness in a vineyard of Argentina
}

\author{
Gabriel Pompozzi (1D - Sofía Copperi • Florencia Fernández Campón • \\ Susana Lagos Silnik · Sol García $\cdot$ Agustina Peralta $\cdot$ Eduardo Albrecht
}

Received: 26 May 2020/ Accepted: 8 October 2020

(C) International Organization for Biological Control (IOBC) 2020

\begin{abstract}
Maintaining biodiversity in agricultural systems is essential, as it plays a key role in ecosystem services provision. However, it is declining at an unprecedented rate. Several methods can contribute to increasing species diversity in agroecosystems, including the use of artificial microhabitats. Studies focusing on biodiversity in vineyards have been carried out recently, mainly in Europe and North America, but are scarce in South America. In this study, we investigate whether introduced environmental variability and habitat complexity, using corrugated cardboard bands, enhances spider abundance and diversity in vineyards. Spiders were collected from grapevine plants, using two collecting methods
\end{abstract}

Handling Editor: Eric Riddick

G. Pompozzi $(\bowtie)$

Sección Entomología, Facultad de Ciencias, Universidad de La República, Iguá 4225, 11400 Montevideo, Uruguay e-mail: gabrielpompozzi@gmail.com

S. Copperi · F. Fernández Campón · S. Lagos Silnik Laboratorio de Entomología, IADIZA (CCT CONICETMendoza), Mendoza, Argentina

F. Fernández Campón

Facultad de Ciencias Exactas y Naturales, Universidad

Nacional de Cuyo, Mendoza, Argentina

S. García · A. Peralta · E. Albrecht Instituto de Biología Animal, Facultad de Ciencias Agrarias, Universidad Nacional de Cuyo, Mendoza, Argentina (foliage beating and direct collection). Plants with and without cardboard bands $(\mathrm{N}=30)$ were sampled in three different phenological stages of the vineyard (veraison, maturity and postharvest). Overall, we collected 904 spiders belonging to 35 species. We found that spider abundance and species richness significantly increased with cardboard bands. In addition, we identified particular species that prefer cardboard bands to build their shelters. Results suggest that cost-effective habitat manipulation can increase spider abundance in vineyards, which implies higher biodiversity conservation value and potential for improving biological control.

Keywords Cardboard bands $\cdot$ Araneae $\cdot$ Natural predators $\cdot$ Agroecosystems $\cdot$ Functional guilds

\section{Introduction}

Biodiversity in agroecosystems is essential for ecosystem services provision (e.g., biological control of pests, maintenance of soil nutrients, etc.) (Landis 2017; Dainese et al. 2019). A remarkable loss in biodiversity has been taking place for several decades in agricultural use areas worldwide, and this problem is far from being solved (Emmerson et al. 2016). Within plantations, natural vegetation provides shelter, places to overwinter, and food for a wide range of natural predators (Geiger et al. 2009). To increase 
biodiversity, habitat alterations that enhance structural complexity within and around crops can be introduced (Altieri and Nicholls 2004). Higher species diversity within a productive system is expected to sustain a more diverse community of beneficial organisms (e.g., predators, parasitoids and entomopathogens) (Altieri et al. 2005).

Habitat structure modification through artificially increasing complexity within agroecosystems is a topic of interest, due to its potential benefits in the context of biological control (Michalko et al. 2017). Greater habitat complexity generally increases the number of natural enemies (Langellotto and Denno 2004), which leads to pest decrease. In addition, it can reduce intra-guild predation by providing shelter for predators of lower trophic levels, reducing predator encounter rates, or leading to lower predator capture rate (Ferreira et al. 2011). Through the generation of habitat alterations, disturbances lead to changes in spider diversity and abundance. For example, Cárdenas et al. (2012) found that spider diversity was not affected by cover-crop removal in an Olive orchard, but it had a positive effect on spider abundance. Additionally, non-cropped fragments have a positive effect on spider abundance and diversity in soybean crops (Pompozzi et al 2019). Indeed, habitat manipulation is used to increase the number of spiders in the field, and it has been tested with different techniques, such as holes in the ground (Alderweireldt 1994), cages (Halaj et al. 2000) and cardboard bands (Bogya et al. 1999; Horton et al. 2001; Isaia et al. 2006a; Korenko and Pekár 2010; Michalko et al. 2017; Salman et al. 2019, 2020). Halaj et al. (2000) used artificial refuges for ground spiders, and showed an increase in spider abundance in these refuges compared to open fields. In addition, the use of artificial retreats to increase spider densities and suppress pest effects in plants was found to be significant for foliage spiders in pear trees (Michalko et al. 2017). Cardboard bands are usually used to collect overwintering moths (Ricci et al. 2009), but are also an effective method to collect other insects and spiders that hide in these cardboard bands (Horton et al. 2001; Lombardini et al. 2005; Michalko et al. 2017). In fact, trunk refuges made with cylindrical corrugated cardboard were recently shown to be effective for the collection of spiders and other arthropods in trees (Salman et al. 2020).
Spiders are an excellent model for agroecosystem studies, and have been the subject of numerous studies in the last years (Rypstra et al. 1999; Sunderland 1999; studies reviewed in Birkhofer et al 2013; RosasRamos et al. 2018; Salman et al. 2019, among others). Spiders have great tolerance to agricultural management. However they are rarely employed as biocontrol agents (Birkhofer et al 2013). This might be due to their wide prey spectrum, although they have been shown to considerably reduce pest populations. Thus they should be considered an important component of biological control (Michalko et al 2019). An important trait of spiders is that they do not constitute a homogeneous functional group. Instead, they exhibit diverse predation strategies, land dispersal modes, and are able to cope with adverse ecological conditions. Spiders have the potential to colonize almost all habitats and microhabitats, and are abundant in both natural and cultivated environments (Marc et al 1999). Due to all these characteristics, spiders are considered a potentially excellent group for limiting pests and acting as bioindicators. Indeed, a recent study shows that spiders contribute to the decline of the populations of various agricultural pests (Michalko et al. 2019). This decrease in pests provides economic and environmental benefits, and diminishes costs (McCravy 2018).

For the sustainable management of many perennial crops, natural predators of pests are a primary tool (Daane et al. 2018). Increasing biodiversity is a common approach, and has become frequent in sustainable systems, mainly at the landscape scale (Landis 2017). Within this context, it is important to address whether simpler habitat management practices, which can be carried out by farmers, would favor the community of natural predators, especially spiders.

Among the different agroecosystems, vineyards have potential for simple habitat manipulations that might influence pest control, reducing the use of pesticides. In addition, vineyards are undergoing a strong expansion worldwide. However, studies on biodiversity in vineyards have only recently been considered. Further, they are carried out mainly in Europe and North America, but are scarce in South America (Paiola et al. 2020). Viticulture is one of the most important economic activities in the Andean foothills of central-west of Argentina (where almost 90\% of Argentine viticulture production takes place) 
and a large portion of the area is occupied by this crop (Barzola-Elizagaray and Engelman 2020). Recently, the grapevine moth (Lobesia botrana Den \& Schiff, a worldwide viticulture pest) has been detected in this region, leading to the use of different control measures, including chemical control (Mendoza et al. 2014). For example, mating disruption with pheromone strips is commonly used against $L$. botrana by farmers, but it is an expensive method. Increasing the number of spiders may contribute to reducing the abundance of grapevine moths (Addante et al. 2008), thereby reducing the use of pesticides and/or pheromone strips.

Here, we examine whether artificially increased habitat complexity using corrugated cardboard bands in a vineyard enhances spider diversity. We hypothesize that the creation of microhabitats in the vineyard increases the number of available refuges, resulting in an increase in spider abundance and diversity.

\section{Materials and methods}

Study area

Spiders were collected from a vineyard located in the area of Barrancas, Maipú Department, Mendoza province, Argentina $\left(33^{\circ} 04^{\prime} 40^{\prime \prime} \mathrm{S}, 68^{\circ} 39^{\prime} 32^{\prime \prime} \mathrm{W}\right.$; Fig. 1). The climate of the region is arid with a mean annual temperature of $15.9{ }^{\circ} \mathrm{C}$. The mean annual precipitation is $220 \mathrm{~mm}$ (data obtained from the National Meteorological Service). Plants in the vineyard were of the Chardonnay variety (vertical shoot positioned trellis, planting frame $1.5 \mathrm{~m}$ between plants $\times 2.4 \mathrm{~m}$ between rows) and were approximately 20 years old, with conventional management (drip irrigation; soil: minimum tillage; spur pruning: bilateral cordon; application of agrochemicals; antihail net).

\section{Experimental design and spider sampling}

We selected 30 pairs of vine plants along a transect placed across planted grapevine rows. In each row, a single pair was selected, leaving a row in between (20 $\mathrm{m}$ apart). The distance between plants of the pair was 3-5 m. One of the plants of each pair acted as a control, while the other was wrapped with corrugated cardboard bands (here after called treatment). To

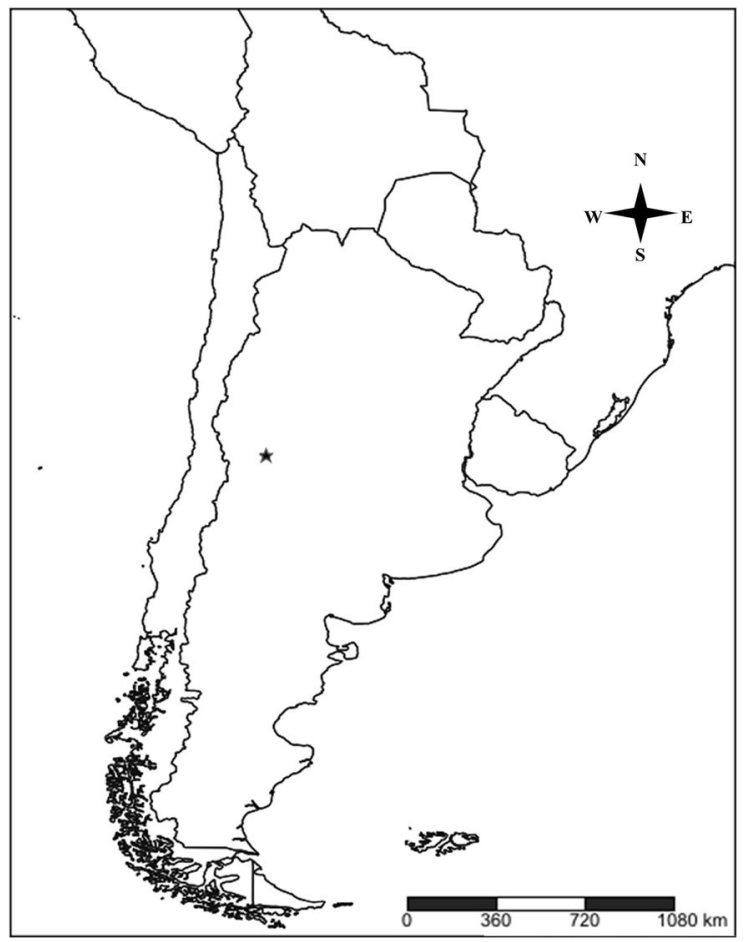

Fig. 1 Location of the studied vineyard (black star) in Mendoza Province, Argentina

avoid spatial effects, we regularly replaced the position of the control and treatment plants within the row. We wrapped the cardboard bands $\left(0.15 \mathrm{~m}^{2}\right.$; $0.30 \times 0.5 \mathrm{~m})$ around the trunk $(10 \mathrm{~cm}$ above the ground) and on the two lateral branches of each plant. The bands were fixed with packing tape, and were wrapped with the same tape to increase their impermeability and to prevent rain damage. We placed the cardboard bands 45 days before each sampling to allow colonization by spiders. We wrapped the cardboard bands to treatment plants on October 15th of 2018, 45 days before the first collecting date. We carried out one-day field collecting on three occasions: December 1st 2018, and on January 15th and March 1st, 2019, corresponding to three different phenological stages of the vineyard (veraison, maturity and post-harvest). We sampled a new pair of plants (control and treatment) at each collection time. For each control and treatment plant, we used two sampling techniques: foliage beating and direct collection. Foliage spiders were collected by beating the plant branches with a wooden stick while holding a white plastic tray under each plant to catch falling 
spiders. Each plant was beaten three times $(30 \mathrm{~s}$ each time). Direct collection consisted of manual sampling of spiders on the bark of the trunk and the branches of each plant for $5 \mathrm{~min}$. The inspection of the cardboard bands in the treatment plants was included within the same searching time to standardize search in the two plants. This guaranteed that the only difference between control and treatment was larger surface provided by the cardboard bands to the treatment plants. We placed the collected spiders in a container properly labeled with $70 \%$ alcohol. Collected specimens were taken to the laboratory, where we identified them at the family level and species/morpho-species. We identified all the collected specimens at the species/morpho-species level even when the identification of immature stages can involve an error. However, the differences between species allowed us to confidently differentiate them, even in the case of immature individuals. Thus, we consider that the error is likely negligible compared to the valuable information obtained. Spiders were assigned to guilds according to the criteria proposed by Uetz et al. (1999), and we used the nomenclature proposed by Uetz et al. (1999) and Cardoso et al. (2011): ambush hunters, foliage hunters, ground hunters, orb web weavers, sheet web weavers, and space web weavers. Voucher specimens were deposited in the arachnological collection of Instituto Argentino de Investigaciones de ZonasÁridas (CAI-IADIZA CONICET). For each collecting method (foliage beating and direct collection) we estimated sampling completeness by comparing observed species/morpho-species with estimated through the non-parametric species richness estimator Chao 1 (Gotelli and Colwell 2009). Both methods showed high values ( $92 \%$ out of 29 estimated species for foliage beating; and $82 \%$ out of 33 estimated species for direct collection). Subsequently, we pooled the spiders collected with the two techniques from the same plant and date.

\section{Data analysis}

We analyzed the overall species abundance and richness (number of species) and guild abundance data with generalized linear mixed models (GLMM) implemented in the "MASS" package of R software (Venables and Ripley 2002) (R Core Team 2019). Models were fitted using a negative binomial distribution and a log link function, as data were over- dispersed and a Poisson distribution was not appropriate. Treatment (with and without cardboard band) and date were considered as the fixed effects, while the row was the random effect. Then, we performed the same analysis including the interaction between treatment and date.

\section{Results}

We collected a total of 904 spiders belonging to 15 families and 35 species/morphospecies (Table 1). The most abundant families were Araneidae $(26.3 \%$ of total), Philodromidae (14.3\%), Gnaphosidae (10.8\%) and Filistatidae (10.3\%). We detected a significant positive effect of cardboard bands on both spider abundance $\quad$ (coefficient $=0.659, \quad \mathrm{SE}=0.137$, $\mathrm{p}<0.001$ ) and richness (coefficient $=0.250, \mathrm{SE}=$ $0.127, p=0.048$ ). We found this same tendency when analyzing each collecting time. Cardboard bands showed positive effects on spider abundance in the first and second dates, but this difference was not significant (Fig. 2). Regarding species richness, control plants (i.e., without cardboard bands) showed a lower number of species than plants with cardboard bands in all collecting times, being significantly lower in the first collection date (coefficient $=-0.433$, $\mathrm{SE}=0.174, \mathrm{p}=0.01259$; Fig. 3).

We recorded six different functional guilds, within which foliage hunters and orb web weavers were the most abundant (Fig. 4). Functional guilds showed different responses to the presence of cardboard bands (Fig. 4). Almost all guilds were not significantly affected by the use of cardboard bands, and only ground hunters were significantly more abundant in plants with cardboard bands than in control plants (coefficient $=2.689, \mathrm{SE}=0.897, \mathrm{p}=0.0027$; Fig. 4 ) The most important family within this guild was Gnaphosidae. We recorded five different species of gnaphosids, and two of them were clearly more abundant in treatment plants (Apodrassodes araucanius and Camillina sp.; Table 1). We also found a positive trend in the abundance of sheet web weavers in plants with cardboard bands, although this difference was not significant (Fig. 4). 
The use of artificial habitats increases spider abundance and richness in a vineyard of...

Table 1 Number of specimens of each species/morpho-species collected in plants with and without cardboard bands

Guilds (and families/species within guilds) are ordered alphabetically

\begin{tabular}{|c|c|c|c|}
\hline Guild/family & Species/morpho-species & With cardboard & Without cardboard \\
\hline \multicolumn{4}{|l|}{ Ambush hunters } \\
\hline Philodromidae & Paracleocnemis sp. & 65 & 64 \\
\hline Thomisidae & Tho-sp1 & 3 & 3 \\
\hline Thomisidae & Misumenops sp. & 1 & 1 \\
\hline Thomisidae & Tmarus sp. & 2 & 1 \\
\hline \multicolumn{4}{|l|}{ Foliage hunters } \\
\hline Anyphaenidae & Any-sp1 & 10 & 12 \\
\hline Anyphaenidae & Sanogasta alticola & 35 & 29 \\
\hline Cheiracanthiidae & Cheiracanthium inclusum & 10 & 6 \\
\hline Corinnidae & Castianeira sp. & 5 & 3 \\
\hline Trachelidae & Meriola cetiformis & 34 & 31 \\
\hline Trochanteridae & Trochanteria robustus & 2 & \\
\hline Salticidae & Sal-sp1 & 2 & 2 \\
\hline Salticidae & Sal-sp2 & 25 & 24 \\
\hline Salticidae & Aphirape sp. & 6 & 16 \\
\hline Salticidae & Phiale roburifoliata & & 3 \\
\hline Sparassidae & Polybetes sp. & 6 & 24 \\
\hline \multicolumn{4}{|l|}{ Ground hunters } \\
\hline Gnaphosidae & Gna-sp1 & 1 & \\
\hline Gnaphosidae & Gna-sp2 & 8 & 13 \\
\hline Gnaphosidae & Apodrassodes araucanius & 42 & 10 \\
\hline Gnaphosidae & Camillina sp. & 17 & 4 \\
\hline Gnaphosidae & Latonigena sp. & 3 & \\
\hline Lycosidae & Lyc-sp1 & & 1 \\
\hline Zodariidae & Cybaeodamus enigmaticus & 2 & \\
\hline \multicolumn{4}{|l|}{ Orb web weavers } \\
\hline Araneidae & Ara-Sp1 & 1 & \\
\hline Araneidae & Ara-Sp2 & 1 & 2 \\
\hline Araneidae & Ara-Sp3 & 2 & 2 \\
\hline Araneidae & Cyclosa serena & 2 & \\
\hline Araneidae & Metepeira sp. & 79 & 98 \\
\hline Araneidae & Ocrepeira venustula & 8 & 1 \\
\hline Araneidae & Parawixia sp. & 22 & 20 \\
\hline \multicolumn{4}{|l|}{ Sheet web weavers } \\
\hline Filistatidae & Pikelinia tambilloi & 55 & 38 \\
\hline Linyphiidae & Lin-sp1 & 4 & 2 \\
\hline Linyphiidae & Lin-sp2 & 1 & \\
\hline Linyphiidae & Lin-sp3 & 1 & 1 \\
\hline \multicolumn{4}{|l|}{ Space web weavers } \\
\hline Theridiidae & Latrodectus geometricus & 1 & \\
\hline Theridiidae & Theridion $\mathrm{sp}$. & 15 & 22 \\
\hline Total & & 471 & 433 \\
\hline Number of species & & 33 & 27 \\
\hline
\end{tabular}




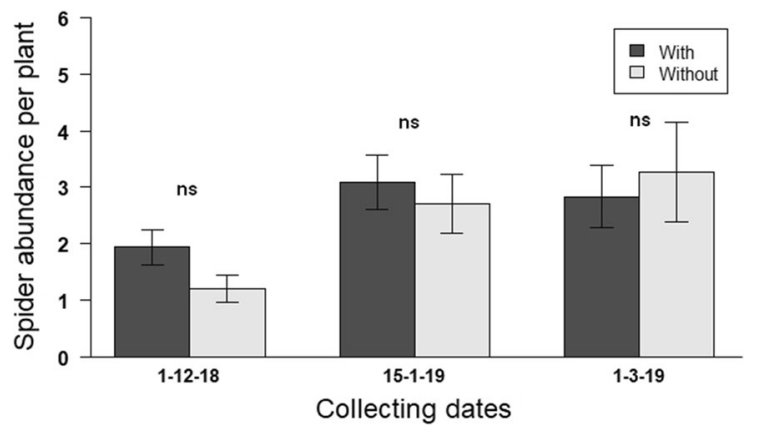

Fig. 2 Spider abundance (mean $\pm \mathrm{SE}$ ) in plants with and without cardboard bands in each collecting time. ns nonsignificant differences

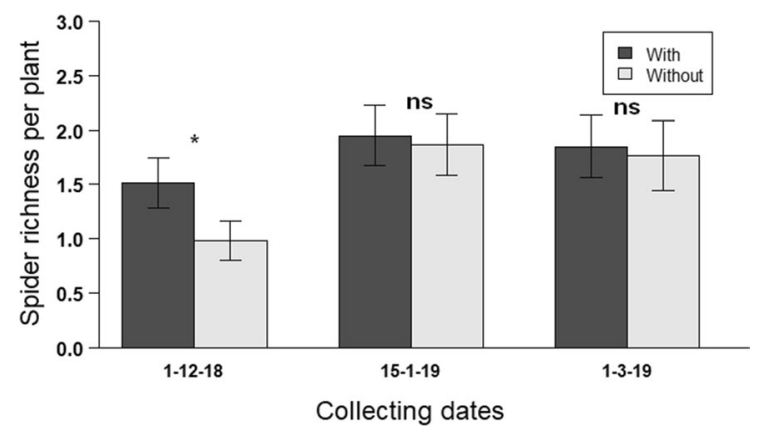

Fig. 3 Spider richness (mean \pm SE) in plants with and without cardboard bands in each collecting time. *Significant difference at $\alpha=0.05$. ns non-significant differences

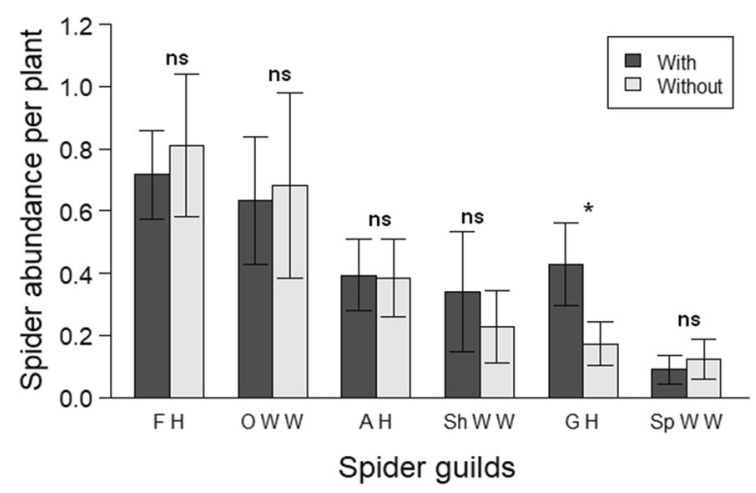

Fig. 4 Spider abundance (mean $\pm \mathrm{SE}$ ) of spider guilds in plants with and without cardboard bands. *Significant difference at $\alpha=0.05$. ns non-significant differences. FH foliage hunters, OWW orb web weavers, AH ambush hunters, ShWW sheet web weavers, GH ground hunters, SpWW space web weavers

\section{Discussion}

We found evidence to support our hypothesis that habitat heterogeneity generated through cardboard bands is effective for increasing spider abundance and richness. The use of cardboard bands is an effective technique to monitor the presence of natural enemies, especially spiders (Horton et al. 2001; Lombardini et al. 2005; Isaia et al. 2006a; Salman et al. 2019, 2020). Even more, it has been demonstrated to improve biocontrol efficiency in pear orchards (Michalko et al. 2017), and it has been widely used in other plantations, such as apples, pomegranates and pecans, mainly in Europe and North America (Lombardini et al. 2005; Korenko and Pekár 2010; Salman et al. 2019). However, to our knowledge, cardboard bands were scarcely used in vineyards (Serra et al. 2006; Havlova et al. 2017). As we found in our study, a diverse group of spiders used cardboard bands and increased their numbers in this homogeneous habitat. Although we carried out the study during the grape production period, the use of cardboard bands might also be important for overwintering spiders (Korenko and Pekár 2010; Michalko et al. 2017), highlighting the need of further exploring this technique in winter. Moreover, Isaia et al. (2006a) compared the efficiency of cardboard bands and other materials, such as polyethylene bubbles wrapped in trees, and they found that polyethylene was more effective. This technique was also used in forests from Canada, with high efficiency to collect spiders (Pinzón and Spence 2010). However, we consider that cardboard is more suitable than polyethylene from an environmental point of view, even when cardboards could be destroyed more easily, for example with frequent rainfalls or high environmental humidity. In this specific case, however, the study region is semi-arid, thus cardboard damaged due to climatic conditions is less likely.

Our findings are in agreement with previous studies that showed increasing spider abundance through the use of cardboard bands (Isaia et al. 2010; Korenko and Pekár 2010; Salman et al. 2020). It is important to point out that this study was carried out in only one vineyard, thus it would be necessary to prove its efficiency in other vineyards of the region, since different species compositions due to local effects might influence biological control on vineyard pests. In pear orchards of Czcech Republic, Michalko et al. 
(2017) confirmed an improvement in biological control, but only if spider density was high. Furthermore, in an apple orchard of Italy, Isaia et al (2010) found that the provision of artificial shelters significantly increased the total number of spiders, and trees showed lower damage. These authors suggested that habitat manipulation in apple orchards increased spider abundance, leading to an increase in their potential preying efficiency. Although we did not record pests during our surveys, we did not observe pest species (e.g. Lepidoptera larvae or other phytophagous insects) on the cardboard bands. This might be due to the fact that larvae or other insects might avoid cardboard bands precisely due to the presence of spiders on them. So far, we know that the use of this technique in vineyards leads to increases in spider abundance, and we could therefore expect positive effects on biocontrol.

Cardboard bands were differentially occupied by spider guilds. Foliage-dwelling spiders, such as foliage hunters and orb web weavers, actually showed a negative response to cardboard bands. This technique might not be as effective in vegetation-dwelling spiders because they use leaves and upper branches to make their shelters. However, we found that cardboard bands benefited ground hunters. These spiders, mainly represented by gnaphosids, were found colonizing the lower part of plants, where they build their shelters. Since these spiders are mainly ground dwellers, direct collection and beating are not suitable to capture them. However, we found a large number using the cardboard bands. Gnaphosid spiders (known as ground spiders) are nocturnal and active ground predators. Most species live under stones and logs, but others build their shelters in barks on small shrubs close to the ground (Bradley 2012). In the vineyard, gnaphosids were abundant, and their abundance increased on the cardboard bands. Apodrassodes araucanius (Chamberlin) was the dominant species within this family, and it was frequently found on the cardboard bands. In fact, we found $A$. araucanius nests with egg sacs under some cardboard bands, indicating that they even use them for oviposition (Pompozzi, pers obs.). This is a medium-sized gnaphosid, and its biology and trophic ecology is little known. Gnaphosid spiders have a wide trophic niche. However, some species have a more specialized diet, hunting large and potentially dangerous prey, including ants and other spiders (Baydizada et al. 2020). The presence of this species in other vineyards of the region is unknown, since no study has addressed spiders of the area. Thus, our results provide baseline knowledge of spider communities in the region, which can contribute to further studies.

Here, we present an alternative that could be used as a complement to other management practices aiming at improving biodiversity (and ecosystem services), and reducing costs and damages in vineyards. Cardboard bands should be used together with other practices, such as the incorporation of native and floral diversity in intercropping rows (Fiedler et al. 2008; James et al. 2015; Wilson et al. 2015; RosasRamos et al. 2018), minimizing pruning and the fungicide use (Pennington et al. 2019), and allowing the presence of surrounding patches of natural vegetation (Isaiaet al. 2006b; Thomson and Hoffmann 2013; Pfingstmann et al. 2019). These simple practices could favor a gradual transition to a more sustainable agriculture production.

The increasing number and richness of spiders using cardboard bands in vineyards may benefit topdown control of harmful insects. In fact, it is an affordable and simple management practice that could be used by farmers to enhance biological control in their vineyards. Further, its use was recently recommended for trees (Salman et al. 2020). However, there might be some undesired outcomes of this practice since, as mentioned above, it might benefit intra-guild predation or could serve as shelter for pests.

The main limitation of our study is that it includes only one study site (i.e., vineyard). A single case study precludes generalization to other areas or could lead to extrapolation bias. However, even when this constitutes a case study, it provides an important baseline due to the lack of knowledge on spider diversity in agroecosystems of the region. In summary, this is one of the first studies on the community of natural enemies in Argentinean vineyards, using a simple and affordable technique to enhance spider abundance. This could ultimately lead to a reduction in the application of agrochemicals.

Acknowledgments We thank two anonymous reviewers and the editor for their helpful comments that greatly improved the manuscript. We would like to thank Bruno Alzugaray for his help in the field. This study was supported by grant SIIP TIPO 1 (A109) provided by Universidad Nacional de Cuyo to EA.

Author contributions GP conceived the study and wrote the first draft of the manuscript. GP, SC, FFC analyzed the data. All 
authors conducted field work and contributed to the improvement of the manuscript.

Data availability The authors confirm that the data supporting the findings of this study are available from the corresponding author (GP), upon reasonable request.

\section{Compliance with ethical standards}

Conflict of interest The authors have no conflict of interest to declare.

Consent to participate All authors consent to participate in this manuscript.

Consent for publication All authors gave final approval for publication.

\section{References}

Addante R, Di Gioia S, Calculli C, Pollice A (2008) The impact of spiders (Araneae) on Lobesia botrana (Denis \& Schiffermüller) population density. IOBC/WPRS Bull 36:221-231

Alderweireldt M (1994) Habitat manipulations increasing spider densities in agroecosystems: possibilities for biological control? J App Entomol 118(1-5):10-16

Altieri MA, Nicholls CI (2004) Biodiversity and pest management in agroecosystems. CRC Press, Boca Raton

Altieri MA, Ponti L, Nicholls CI (2005) Enhanced pest management through soil health: toward a blow ground habitat management strategy. Biodynamics 253:33-40

Barzola-Elizagaray P, Engelman A (2020) La vitivinicultura en Mendoza desde 1990: entre la globalización y el desarrollo regional. Íconos Rev Cs Social 66:191-212 (In Spanish)

Baydizada N, Tóthová A, Pekár S (2020) Tracing the evolution of trophic specialization and mode of attack behaviour in the ground spider family Gnaphosidae. Org Divers Evol. https://doi.org/10.1007/s13127-020-00453-0

Birkhofer K, Entling MH, Lubin Y (2013) Agroecology: trait composition, spatial relationships, trophic interactions. In: Penney D (ed) Spider research in the $21^{\text {st }}$ century: trends \& perspectives. Siri Scientific Press, Rochdale, pp 200-228

Bogya S, Szinetár C, Markó V (1999) Species composition of spider (Araneae) assemblages in apple and pear orchards in the Carpathian Basin. Acta Phytopathol Entomol Hung 34(1/2):99-122

Bradley RA (2012) Common spiders of North America. Univ of California Press, Berkeley

Cárdenas M, Castro J, Campos M (2012) Short-term response of soil spiders to cover-crop removal in an organic olive orchard in a Mediterranean setting. J Insect Sci 12(1):61

Cardoso P, Pekár S, Jocqué R, Coddington JA (2011) Global patterns of guild composition and functional diversity of spiders. PLoS ONE 6(6):e21710

Gotelli JE, Colwell RK (2009) Estimating species richness. In: Magurran AE, McGill BJ (eds) Biological diversity: frontiers in measurement and assessment. Oxford University Press, Oxford, pp 39-54

Daane KM, Vincent C, Isaacs R, Ioriatti C (2018) Entomological opportunities and challenges for sustainable viticulture in a global market. Annu Rev Entomol 63:193-214

Dainese M, Martin EA, Aizen MA, Albrecht M, Bartomeus I, Bommarco R, Carvalheiro LG, Chaplin-Kramer R, Gagic V, Garibaldi LA, Ghazoul J, Grab H, Jonsson M, Karp DS, Kennedy CM, Kleijn D, Kremen C, Landis DA, Letourneau DK, Marini L, Poveda K, Rader R, Smith HG, Tscharnke T, Andersson GKS, Badenhausser I, Baensch S, Bezerra AD, Bianchi FJJA, Boreux V, Bretagnolle V, Caballero-Lopez B, Cavigliasso P, Cetkovic A, Chacoff NP, Classen A, Cusser S, da Silva FD, de Groot GA, Dudenhöffer JH, Ekroos J, Fijen T, Franck P, Freitas BM, Garratt MPD, Gratton C, Hipólito J, Holzschuh A, Hunt L, Iverson AL, Jha S, Keasar T, Kim TN, Kishinevsky M, Klatt BK, Klein AM, Krewenka KM, Krishnan S, Larsen AE, Lavigne C, Liere H, Mass B, Mallinger RE, Martinez Pachon E, Martinez-Salinas A, Meehan TD, Mitchell MGE, Molina GAR, Nesper M, Nilsson L, O'Rourke ME, Peters MK, Plecas M, Potts SG, Ramos DL, Rosenheim JA, Schmack J, Sciligo AR, Seymour C, Stanley DA, Stewart R, Stout JC, Sutter L, Takada MB, Taki H, Tamburini G, Tschumi M, Viana BF, Westphal C, Willcox BK, Wratten SD, Yoshioka A, Zaragoza-Trello C, Zhang W, Zou I, Steffan-Dewenter I (2019) A global synthesis reveals biodiversity-mediated benefits for crop production. Sci Adv 5(10):eaax0121

Emmerson M, Morales MB, Oñate JJ, Batary P, Berendse F, Liira J, Aavik T, Guerrero I, Bommarco R, Eggers S, Tscharntke T, Weisser WW, Clément L, Bengtsson J (2016) How agricultural intensification affects biodiversity and ecosystem services. In: Dumbrell AJ, Kordas RL (eds) Advances in ecological research, vol 55. Academic Press, Cambridge, pp 43-97

Ferreira JAM, Cunha DFS, Pallini A, Sabelis MW, Janssen A (2011) Leaf domatia reduce intraguild predation among predatory mites. Ecol Entomol 36:435-441

Fiedler AK, Landis DA, Wratten SD (2008) Maximizing ecosystem services from conservation biological control: the role of habitat management. Biol Control 45(2):254-271

Geiger F, Wäckers FL, Bianchi FJJA (2009) Hibernation of predatory arthropods in semi-natural habitats. BioControl 54:529-535

Halaj J, Cady AB, Uetz GW (2000) Modular habitat refugia enhance generalist predators and lower plant damage in soybeans. Environ Entomol 29(2):383-393

Havlova L, Hula V, Niedobova J, Michalko R (2017) Effect of adjacent steppe-like habitats on spider diversity in vine plants. BioControl 62(6):757-768

Horton DR, Miliczky ER, Broers DA, Lewis RR, Calkins CO (2001) Numbers, diversity, and phenology of spiders (Araneae) overwintering in cardboard bands placed in pear and apple orchards of central Washington. Ann Entomol Soc Am 94(3):405-414

Isaia M, Bona F, Badino G (2006a) Comparison of polyethylene bubble wrap and corrugated cardboard traps for sampling tree-inhabiting spiders. Environ Entomol 35(6):1654-1660 
Isaia M, Bona F, Badino G (2006b) Influence of landscape diversity and agricultural practices on spider assemblage in Italian vineyards of Langa Astigiana (Northwest Italy). Environ Entomol 35(2):297-307

Isaia M, Beikes S, Paschetta M, Sarvajayakesavalu SN, Badino G (2010) Spiders as biological controller in apple orchards infested by Cydia spp. In XXIV European congress of arachnology. Natural History Museum, Bern, pp 79-88

James DG, Seymour L, Lauby G, Buckley K (2015) Beauty with benefits: butterfly conservation in Washington State, USA, wine grape vineyards. J Insect Conserv 19(2):341-348

Korenko S, Pekár S (2010) Is there intraguild predation between winter-active spiders (Araneae) on apple tree bark? Biol Control 54(3):206-212

Landis DA (2017) Designing agricultural landscapes for biodiversity-based ecosystem services. Basic Appl Ecol 18:1-12

Langellotto GA, Denno RF (2004) Responses of invertebrate natural enemies to complex-structured habitats: a metaanalytical synthesis. Oecologia 139:1-10

Lombardini L, Harris MK, Glenn DM (2005) Effects of particle film application on leaf gas exchange, water relations, nut yield, and insect populations in mature pecan trees. Hort Sci 40(5):1376-1380

Marc P, Canard A, Ysnel F (1999) Spiders (Araneae) useful for pest limitation and bioindication. Agric Ecosyst Environ 74:229-273

McCravy KW (2018) A review of sampling and monitoring methods for beneficial arthropods in agroecosystems. Insects 9(4): 170

Mendoza G, Sánchez J, Becerra V (2014) Impacto ambiental de tres estrategias fitosanitarias para el control de Lobesia botrana. In: $37^{\text {th }}$ World congress of vine and wine and $12^{\text {th }}$ general assembly of the OIV (Part 2). EDP Sciences. p 05009 (In Spanish)

Michalko R, Petráková L, Senstenská L, Pekár S (2017) The effect of increased habitat complexity and density-dependent non-consumptive interference on pest suppression by winter-active spiders. Agric Ecosyst Environ 242:26-33

Michalko R, Pekár S, Dul'a M, Entling MH (2019) Global patterns in the biocontrol efficacy of spiders: a meta-analysis. Glob Ecol Biogeogr 28(9):1366-1378

Paiola A, Assandri G, Brambilla M, Zottini M, Pedrini P, Nascimbene J (2020) Exploring the potential of vineyards for biodiversity conservation and delivery of biodiversitymediated ecosystem services: a global-scale systematic review. Sci Total Environ 706:135839

Pennington T, Kolb S, Kaiser J, Hoffmann C, Entling MH (2019) Does minimal pruning and reduced fungicide use impact spiders in the grapevine canopy? J Arachnol 47(3):381-384

Pfingstmann A, Paredes D, Buchholz J, Querner P, Bauer T, Strauss P, Kratschmer S, Winter S, Zaller J (2019) Contrasting effects of tillage and landscape structure on spiders and springtails in vineyards. Sustainability 11(7):2095

Pinzón J, Spence JR (2010) Bark-dwelling spider assemblages (Araneae) in the boreal forest: dominance, diversity, composition and life-histories. $\mathrm{J}$ Insect Conserv 14:439-458
Pompozzi G, Marrero HJ, Haedo J, Fritz L, Torretta JP (2019) Non-cropped fragments as important spider reservoirs in a Pampean agro-ecosystem. Ann App Biol 175(3):326-335

R Core Team (2019) R: a language and environment for statistical computing. R Foundation for Statistical Computing, Vienna. https://www.r-project.org/

Ricci B, Franck P, Toubon JF, BouvierJC SB, Lavigne C (2009) The influence of landscape on insect pest dynamics: a case study in southeastern France. Landsc Ecol 24(3):337-349

Rosas-Ramos N, Baños-Picón L, Tobajas E, de Paz V, Tormos J, Asís JD (2018) Value of ecological infrastructure diversity in the maintenance of spider assemblages: a case study of Mediterranean vineyard agroecosystems. Agric Ecosyst Environ 265:244-253

Rypstra AL, Carter PE, Balfour RA, Marshall SD (1999) Architectural features of agricultural habitats and their impact on the spider inhabitants. J Arachnol 27:371-377

Salman IN, Gavish-Regev E, Saltz D, Lubin Y (2019) The agricultural landscape matters: spider diversity and abundance in pomegranate orchards as a case study. BioControl 64(5):583-593

Salman IN, Ferrante M, Möller DM, Gavish-Regev E, Lubin Y (2020) Trunk refugia: a simple, inexpensive method for sampling tree trunk arthropods. J Insect Sci 20(2):5

Serra G, Lentini A, Verdinelli M, Delrio G (2006) Effects of cover crop management on grape pests in a Mediterranean environment. IOBC/WPRS Bull 29(11):209-214

Sunderland K (1999) Mechanisms underlying the effects of spiders on pest populations. J Arachnol 27:308-316

Thomson LJ, Hoffmann AA (2013) Spatial scale of benefits from adjacent woody vegetation on natural enemies within vineyards. Biol Control 64(1):57-65

Uetz GW, Halaj J, Cady AB (1999) Guild structure of spiders in major crops. J Arachnol 27:270-280

Venables WN, Ripley BD (2002) Modern applied statistics with $\mathrm{S}, 4^{\text {th }}$ edn. Springer, New York

Wilson H, Miles AF, Daane KM, Altieri MA (2015) Landscape diversity and crop vigor influence biological control of the western grape leafhopper (E. elegantula Osborn) in vineyards. PLoS ONE 10(11):e0141752

Gabriel Pompozzi is a post-doctoral researcher at Universidad de la República, Uruguay. His research is focuses on diversity and ecology of spiders in different agroecosystems.

Sofía Copperi is a post-doctoral researcher at the Argentine Dryland Research Institute (IADIZA-CONICET), Argentina. Her research interest includes spider behavior and ecology.

Florencia Fernández Campón is a researcher at IADIZACONICET, Argentina. She is working on spider ecology in natural and disturbed environments of Andean region.

Susana Lagos Silnik is the curator of the arachnological collection of the IADIZA-CONICET, Argentina. Her research is focus on spider diversity and ecology. 
Sol García is a graduate student at Universidad Nacional de Cuyo (UNCuyo), Argentina. She is interested in spider ecology and diversity.

Agustina Peralta is a graduate student at UNCuyo, Argentina. She is interested in spider ecology and diversity.
Eduardo Albrecht is a professor at UNCuyo, Argentina. He is interested in invertebrates associated with agroecosystems and supervises students in this field. 